\title{
Physical activity as a determinant of total energy expenditure in critically ill children.
}

Citation for published version (APA):

van der Kuip, M., de Meer, K., Westerterp, K. R., \& Gemke, R. J. (2007). Physical activity as a determinant of total energy expenditure in critically ill children. Clinical Nutrition, 26(6), 744-751. https://doi.org/10.1016/j.clnu.2007.08.005

Document status and date:

Published: 01/01/2007

DOI:

10.1016/j.clnu.2007.08.005

Document Version:

Publisher's PDF, also known as Version of record

Document license:

Taverne

\section{Please check the document version of this publication:}

- A submitted manuscript is the version of the article upon submission and before peer-review. There can be important differences between the submitted version and the official published version of record.

People interested in the research are advised to contact the author for the final version of the publication, or visit the DOI to the publisher's website.

- The final author version and the galley proof are versions of the publication after peer review.

- The final published version features the final layout of the paper including the volume, issue and page numbers.

Link to publication

\footnotetext{
General rights rights.

- You may freely distribute the URL identifying the publication in the public portal. please follow below link for the End User Agreement:

www.umlib.nl/taverne-license

Take down policy

If you believe that this document breaches copyright please contact us at:

repository@maastrichtuniversity.nl

providing details and we will investigate your claim.
}

Copyright and moral rights for the publications made accessible in the public portal are retained by the authors and/or other copyright owners and it is a condition of accessing publications that users recognise and abide by the legal requirements associated with these

- Users may download and print one copy of any publication from the public portal for the purpose of private study or research.

- You may not further distribute the material or use it for any profit-making activity or commercial gain

If the publication is distributed under the terms of Article $25 \mathrm{fa}$ of the Dutch Copyright Act, indicated by the "Taverne" license above, 


\title{
Physical activity as a determinant of total energy expenditure in critically ill children
}

\author{
Martijn van der Kuip ${ }^{a, *}$, Kees de Meer $^{a}$, Klaas R. Westerterp ${ }^{b}$, \\ Reinoud J. Gemke ${ }^{a}$
}

\begin{abstract}
a Department of Paediatrics, VU University Medical Center, P.O. Box 7057, 1007 MB Amsterdam, The Netherlands
${ }^{\mathrm{b}}$ Department of Human Biology, Maastricht University, P.O. Box 616, 6200 MD Maastricht, The Netherlands
\end{abstract}

Received 4 January 2007; accepted 19 August 2007

\section{KEYWORDS}

Energy expenditure; Indirect calorimetry; Doubly labelled water; Accelerometry; Paediatric intensive care; Nutritional support

\begin{abstract}
Summary
Background \& aims: For adequate nutritional support of critically ill children, knowledge of the patient's energy expenditure is required. Steady state measurement by a metabolic monitor are defined as resting energy expenditure and may underestimate total energy expenditure in clinical practise. The aim of this study was to investigate total energy expenditure, resting energy expenditure and the relation with physical activity during critical illness and initial recovery.

Methods: We enrolled 20 patients $(0-16 \mathrm{yr})$ with sepsis or following surgery. During the first week following admission, total energy expenditure was measured with doubly labelled water, and compared with daily resting energy expenditure measurements (metabolic monitor). Activity levels were independently determined by tri-axial accelerometry.

Results: Resting energy expenditure was not different from Schofield's predicted basal metabolic rate, but was $20 \%$ lower than total energy expenditure $(P=0.006)$. Overall physical activity level ( $=$ total energy expenditure divided by resting energy expenditure) was $1.22(95 \% \mathrm{Cl}: 1.08-1.36)$ and activity related energy expenditure ( = total energy expenditure minus resting energy expenditure) was associated with accelerometry recordings $\left(R^{2}=0.72, P=0.02\right)$.
\end{abstract}

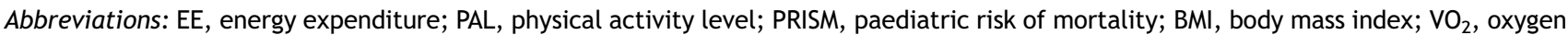
consumption; $\mathrm{VCO}_{2}$, carbon dioxide production; RQ, respiratory quotient

*Corresponding author. Tel.: +31 617068997; fax: +31 204442918.

E-mail addresses: m.vanderkuip@vumc.nl (M. van der Kuip), novosilski@hotmail.com (K. de Meer), k.westerterp@hb.unimaas.nl (K.R. Westerterp), rjbj.gemke@vumc.nl (R.J. Gemke).
} 
Conclusions: During the week following pediatric intensive care admission, in the individual critically ill patient, activity related energy expenditure should be taken into account to prevent a negative energy balance.

(c) 2007 Published by Elsevier Ltd.

\section{Introduction}

In critically ill children, malnutrition due to negative energy balance is often present and a contributing factor for morbidity. ${ }^{1,2}$ Disorders afflicting critically ill children are known to alter energy expenditure (EE). For instance, elevated $E E$ is found in children with burns, neonatal septicaemia, congenital heart disease and head injury. ${ }^{3-6}$ Drugs used for sedation and muscle paralysis during mechanical ventilation decrease EE. ${ }^{7-9}$ In the individual patient, the combination of diagnosis, treatment, age, and other factors such as fever and physical activity make the prediction of energy requirements compounded. Energy requirements are commonly determined using predictive equations of $\mathrm{EE}$, derived from data of healthy subjects, ${ }^{10}$ but may not be accurate in ill individuals. Studies evaluating these equations in critically ill children show low agreement (errors up to $40 \%$ ) for the individual patient's EE. ${ }^{8,11-13}$ Therefore, accurate assessment of total EE is an essential tool for nutritional support in critically ill children.

In the clinical setting, resting $\mathrm{EE}$ is measured with a metabolic monitor, but it is not known whether these measurements match total EE during stay at the paediatric intensive care and thereafter during recovery. In healthy children, differences between total and resting EE can mainly be attributed to physical activity. In critically ill adults, routine intensive care activities such as washing and physical examination were shown to increase resting $\mathrm{EE}$ up to $35 \% .{ }^{14,15}$ Overall, the ratio of total and resting EE, i.e. the physical activity level (PAL), was not higher than 1.10 in these studies, indicating an underestimation of total EE from resting $E E$ measurements with approximately $10 \%$. In children, who have a relatively high EE for body size and limited energy reserve, the relation between resting and total EE might be different from adults. Furthermore, it is not known whether common paediatric intensive care admission diagnoses such as sepsis and major surgery have a different effect on PAL.

The objective of the present study was to measure total $\mathrm{EE}$, daily resting $\mathrm{EE}$, and activity patterns in critically ill children with severe sepsis or septic shock and children who underwent major surgery, during the week following paediatric intensive care admission. We hypothesised that the difference between total $E E$ and resting $E E$, defined as activity related EE may vary between paediatric intensive care patients and may be explained by differences in physical activity.

\section{Materials and methods}

\section{Design}

We conducted an observational cohort study in patients admitted to the paediatric intensive care unit of the VU
University Medical Center between January 2002 and December 2003. Within $24 \mathrm{~h}$ following admission, a doubly labelled water protocol was started to measure total EE during 6 days. Daily resting EE measurements with a metabolic monitor were conducted during this time period. After discharge from the paediatric intensive care unit (usually the day after weaning from mechanical ventilation), the study protocol was continued at a paediatric (high or medium care) ward of our hospital. Physical activity was measured by tri-axial accelerometry during the doubly labelled water protocol. Accelerometry was introduced halfway the study, without prior knowledge to the attending personnel. The institutional review board approved the study and informed consent was obtained from the parents of all patients.

\section{Participants}

Patients were included when diagnosed with severe sepsis or septic shock, according to the American College of Chest Physicians/Society of Critical Care Medicine consensus of sepsis classification, ${ }^{16}$ or following major surgery (abdominal, thoracic or trauma). Patients with known chromosomal anomalies, metabolic disorders or severe brain injury (Glasgow coma scale $<8$ ) were not considered eligible.

A total of 7 sepsis and 13 surgery patients were included. At study entry ( 1 day after admission), all patients were in stable haemodynamic condition, as indicated by blood pressure, heart rate and serum creatinine concentration within two SD of age related values. ${ }^{11}$ Sixteen patients needed respiratory support during some part of the study period, and four patients were weaned from mechanical ventilation before study entry. Mechanical ventilation was performed with a Servo 300A ventilator (Siemens-Elema, Solna, Sweden) with an $\mathrm{F}_{\mathrm{i}} \mathrm{O}_{2}<0.6$ and endotracheal tube leakage $<10 \%$. ${ }^{11}$

Nutritional requirements were determined by the attending physician or consulted dietician. Eleven patients ( 2 with sepsis and 9 after surgery) received enteral feedings exclusively (Nutrison Standard or Nutrini, Nutricia, Zoetermeer, The Netherlands). The other 9 patients received parenteral nutrition, which was provided by the hospital pharmacy in all-in-one mixtures with an energy density between 2.3 and $4.7 \mathrm{MJ} \mathrm{L}^{-1}$ (glucose: $73 \%$, protein: $12 \%$ and fat: $15 \%)$. They were administered according to age and body weight to 5 sepsis and 4 surgery patients.

\section{Measurements}

\section{Clinical characteristics}

Days of mechanical ventilation (including sedation and pharmacological muscle paralysis) were recorded and paediatric risk of mortality (PRISM) scores were calculated. The PRISM score is a measure of severity of illness and is 
composed of physiologic clinical and laboratory variables. It is based on the observation that the amount and extent of physiologic dysfunction is related to the patient's mortality. ${ }^{17}$ As soon as the clinical situation permitted, body weight was measured with a Mettler PM15 scale (MettlerToledo, Colombus, OH, USA) or Scale-tronix 2001 sling scale (Scale-tronix, Carol Stream, IL, USA). Supine length was measured with a stadiometer. Body mass index (BMI) was calculated and SD scores for body weight, height and BMI were determined using Dutch reference values. ${ }^{18}$ Body temperature was measured 4-12 times per day (depending on the patient's condition) with an electronic thermometer (Hartmann BV, Nijmegen, The Netherlands). Total energy intake was calculated from the energy content of (par)enteral feedings and intravenous solutions. Medication was recorded from daily lists that were kept by the nursing personnel.

Total EE from the doubly labelled water method A weighted dose of water $\left(2 \mathrm{~mL} \mathrm{~kg}^{-1}\right)$ with a measured enrichment of 5 atom percent ${ }^{2} \mathrm{H}$ and 10 atom percent ${ }^{18} \mathrm{O}$ was administered through the nasogastric tube. Before administration, a baseline urine sample was collected. Additional urine samples were collected after $4 \mathrm{~h}$, on day 3 and on the last day of the study (usually day 6). Samples were analysed on an isotope-ratio mass spectrometer (Optima; VG Isogas, Middlewich Cheshire, UK) with a CV of $0.02 \%$. Total body water was estimated from the ${ }^{18} \mathrm{O}$ and ${ }^{2} \mathrm{H}$ dilution spaces after the $4 \mathrm{~h}$ equilibration period, and total $\mathrm{CO}_{2}$ production was calculated from the difference in isotope decay curves of ${ }^{18} \mathrm{O}$ and ${ }^{2} \mathrm{H} .{ }^{19}$

\section{Resting EE from the metabolic monitor}

Resting oxygen consumption $\left(\mathrm{VO}_{2}\right)$, carbon dioxide production $\left(\mathrm{VCO}_{2}\right)$ and respiratory quotient $(\mathrm{RQ})$ were measured with a metabolic monitor (Deltatrac II MBM-200, DatexOhmeda, Helsinki, Finland) as previously described. ${ }^{11}$ The accuracy of the monitor was assessed prior to the study with a butane burning system. Calibrations by alcohol burning were performed regularly during the study period. Before each measurement gas calibration was performed with a calibration mixture of $95 \% \mathrm{O}_{2}$ and $5 \% \mathrm{CO}_{2}$. While mechanically ventilated, diagnostic or nursing procedures were withheld during metabolic monitor measurements. After weaning from mechanical ventilation, canopy measurements of the supine, spontaneously breathing patients were also performed during quiescence.

\section{Accelerometry}

Physical activity was measured by a tri-axial accelerometer (Tracmor, Philips Research, Eindhoven, the Netherlands), which was described and validated previously. ${ }^{20}$ The accelerometer $(30 \mathrm{~g})$ was worn in a bandage belt, around the patient's waist for $24 \mathrm{~h} \mathrm{~d}^{-1}$ until the last urine sample for the doubly labelled water method had been collected. The device calculates the sum of rectified and integrated acceleration curves from the antero-posterior, mediolateral and vertical directions of the trunk. The integration period was set at $1 \mathrm{~min}$ and the final output is expressed as kilo counts per day $\left(\right.$ kcounts $\left.^{-1}\right)$. Data were read out automatically after the measuring period had been completed.

\section{Calculations}

For the doubly labelled water method, $\mathrm{VO}_{2}$ was calculated from $\mathrm{VCO}_{2}$ and individual $\mathrm{RQ}$ as measured with the metabolic monitor $\left(\mathrm{VO}_{2}=\mathrm{VCO}_{2} / \mathrm{RQ}_{\text {metabolic monitor }}\right)$. Total and resting $\mathrm{EE}$ were calculated from $\mathrm{VO}_{2}$ and $\mathrm{VCO}_{2}$ using the modified Weir formula. ${ }^{21}$ From the overall total $\mathrm{EE}$ and averaged daily resting EE measurements, activity related EE ( = total EE minus resting EE) and PAL ( = total EE divided by resting EE) were calculated. The metabolic index was calculated as resting EE divided by Schofield's predicted basal metabolic rate. ${ }^{10}$

\section{Statistical analysis}

Data are presented as mean with $95 \%$ confidence interval unless otherwise indicated. Averaged resting EE results were compared to total EE with a paired $t$ test. Data of the surgery and sepsis group were compared with unpaired $t$ tests. Linear regression was performed to explore relations between EE parameters, body weight and accelerometry. Comparisons of the regression equations for total and resting EE with body weight were performed using the method of generalised estimating equations, to correct for differences in the number of metabolic monitor measurements between patients. SPSS 9.0 (SPSS Inc., Chicago, IL, USA) and STATA 7.0 (StataCorp LP, College Station, TX, USA) were used for analyses. For all comparisons $P<0.05$ was considered significant (two-tailed).

\section{Results}

Characteristics of the 20 patients are shown in Table 1. Sixteen patients received mechanical ventilation while sedated with midazolam during a mean period of 4 days (range: 1-7). Five of the mechanically ventilated patients required muscle paralysis with vecuronium during 4 days (range: 3-6). Eight ventilated patients also received inotropic drugs (dopamine, dobutamine and/or norepinephrin), during 4 days (range: $3-6)$. Children with sepsis had a more severe clinical condition, as indicated by a 2-fold higher PRISM score, than those following surgery. In the sepsis group, duration of mechanical ventilation, sedation and muscle paralysis was significantly longer compared to the surgery group.

\section{Energy expenditure}

For all patients combined, mean total EE $\left(230 \mathrm{~kJ} \mathrm{~kg}^{-1} \mathrm{~d}^{-1}\right.$ [95\% Cl: 191-268]) was significantly higher than resting $\mathrm{EE}$ (187 kJ kg $\mathrm{d}^{-1}$ [95\% Cl: 165-209], $\left.P=0.006\right)$. The individually paired data of total and resting $E E$, related to body weight are depicted in Figure 1, and show a constant mean difference, independent of body weight as shown by the parallel regression lines. This difference, i.e. activity related EE was $42(16-68) \mathrm{kJ} \mathrm{kg}^{-1} \mathrm{~d}^{-1}$. For all patients, PAL was significantly higher than 1.00 (mean: 1.22; [95\% Cl: 
Table 1 Patient characteristics.

\begin{tabular}{|c|c|c|c|}
\hline & Surgery* $(N=7)$ & Sepsis $^{\dagger}(N=7)$ & Combined $(N=20)$ \\
\hline Gender (M/F) & $6 / 7$ & $4 / 3$ & $10 / 10$ \\
\hline Age $(y r)$ & $6(6)$ & $4(5)$ & $5(6)$ \\
\hline \multicolumn{4}{|l|}{ Body weight } \\
\hline (kg) & $22(17)$ & $17(15)$ & $20(16)$ \\
\hline (SDS) & $-1.1(1.8)$ & $-0.4(1.9)$ & $-0.8(1.8)$ \\
\hline \multicolumn{4}{|l|}{ Height } \\
\hline$(\mathrm{cm})$ & $109(44)$ & $91(38)$ & $103(42)$ \\
\hline (SDS) & $-1.1(2.7)$ & $-0.7(3.0)$ & $-1.0(2.8)$ \\
\hline \multicolumn{4}{|l|}{ Body mass index } \\
\hline$\left(\mathrm{kg} \mathrm{m}^{-2}\right)$ & $16(2)$ & $17(3)$ & $16(3)$ \\
\hline (SDS) & $-0.4(1.9)$ & $0.6(3.1)$ & $-0.1(2.3)$ \\
\hline Total body water $(\mathrm{L})$ & $16(11)$ & $12(8)$ & $14(10)$ \\
\hline Body temperature $\left({ }^{\circ} \mathrm{C}\right)$ & $37.2(0.3)$ & $37.4(0.6)$ & $37.3(0.4)$ \\
\hline PRISM score & $8(6)$ & $17(6)$ & $11(7)$ \\
\hline Mechanical ventilation and sedation $(\mathrm{d})$ & $2(2)$ & $5(2)$ & $3(3)$ \\
\hline Pharmacological muscle paralysis $(\mathrm{d})^{*}$ & $0(1)$ & $3(3)$ & $1(2)$ \\
\hline
\end{tabular}

Values are mean (SD).

*Individual patients underwent abdominal surgery for Hirschprung's disease $(N=1)$, anorectal malformation $(N=1)$, gastric reflux $(N=1)$, hepatoblastoma $(N=1)$, nephroblastoma $(N=1)$, rhabdomyosarcoma $(N=1)$, or neuroblastoma $(N=2)$ or underwent thoracic surgery for oesophageal atresia $(N=1)$, pectus carinatum $(N=1)$ or pectus excavatum $(N=2)$, or surgical fixation of upper leg fracture due to major trauma $(N=1)$.

Severe sepsis or septic shock, caused by $N$. meningitidis $(N=3)$, following peritonitis $(N=3)$, or pneumonia $(N=1)$.

ISignificant difference between sepsis and surgery group, $P<0.01$.

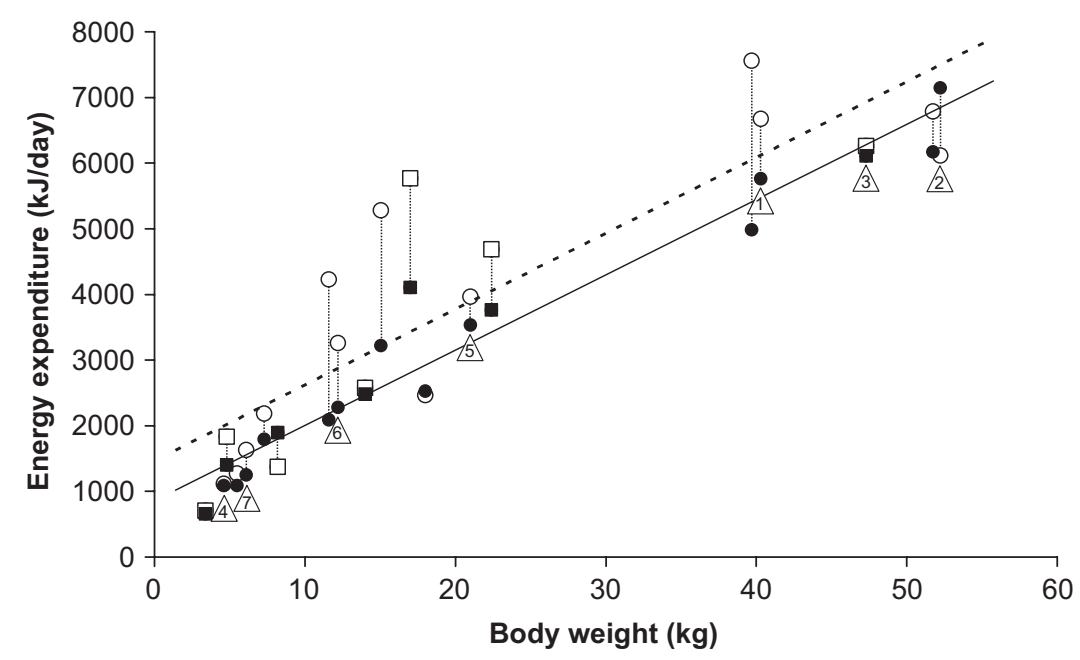

Figure 1 Relationship between total EE in patients with sepsis $(\square, N=7)$ and following surgery $(O, N=13)$, resting $E E(\square$, sepsis; -, surgery) and body weight. Paired data for each individual are interconnected by dotted vertical lines. Numbers 1-7 in triangles point at paired EE data of patients that underwent the accelerometry study and correspond with the numbers in Figure 2 . Dashed line depicts regression line for total EE $\left(N=20 ; Y\left(\mathrm{~kJ} \mathrm{~d}^{-1}\right)=115 X(\mathrm{~kg})+1460 ; R^{2}=0.75\right)$. Solid line depicts regression line for resting EE $\left(N=20 ; Y\left(\mathrm{~kJ} \mathrm{~d}^{-1}\right)=114 X(\mathrm{~kg})+864 ; R^{2}=0.95\right)$. The vertical difference between both regression lines represents activity related EE: 620 (200) $\mathrm{kJ} \mathrm{d}^{-1}, P=0.006$. Regression analyses in subgroups showed no statistical differences between both diagnostic groups.

1.08-1.36]). Resting EE was not significantly different from predicted basal metabolic rate according to Schofield as indicated by a metabolic index of 0.98 (0.90-1.06). Total EE, resting $\mathrm{EE}$, activity related $\mathrm{EE}$, and $\mathrm{PAL}$ were neither significantly different between the sepsis and surgery group (Table 2), nor correlated with the PRISM score. Individual total EE was associated with age $\left(R^{2}=0.70, P<0.0001\right)$ and body weight $\left(R^{2}=0.75, P<0.0001\right)$. Also, mean resting $\mathrm{EE}$ was associated with the same variables $\left(R^{2}=0.92\right.$, $P<0.0001$ and $\left.R^{2}=0.95, P<0.0001\right)$, but activity related EE was not $\left(R^{2}=0.05, P=0.36\right.$ and $\left.R^{2}=0.04, P=0.38\right)$.

Energy intake was significantly higher in the sepsis group compared to the surgery patients in whom intake matched only $74 \%$ of resting $\mathrm{EE}$. Compared to total $\mathrm{EE}$, the sepsis 
Table 2 Energy expenditure and energy intake.

\begin{tabular}{|c|c|c|c|}
\hline & Surgery $(N=13)$ & Sepsis $(N=7)$ & Combined $(N=20)$ \\
\hline \multicolumn{4}{|l|}{ Energy expenditure $\left(\mathrm{kJ} \mathrm{kg}^{-1} \mathrm{~d}^{-1}\right)$} \\
\hline Total* & $229(22)$ & $232(35)$ & $230(191-268)$ \\
\hline Resting $^{\dagger}$ & $178(11)$ & $204(20)$ & 187 (165-209) \\
\hline Activity related & $\overline{50(16)}$ & $\overline{27(21)}$ & $\overline{42(16-68)}$ \\
\hline Physical activity level & $1.27(0.09)$ & $1.12(0.09)$ & $1.22(1.08-1.36)$ \\
\hline \multicolumn{4}{|l|}{ Energy intake } \\
\hline Total $\left(\mathrm{kJ} \mathrm{kg}^{-1} \mathrm{~d}^{-1}\right)^{\ddagger}$ & $141(23)$ & $246(36)$ & $178(131-224)$ \\
\hline As $\%$ of resting energy expenditure & $74(8)$ & $120(13)$ & $90(72-107)$ \\
\hline As $\%$ of total energy expenditure & $61(7)$ & $113(16)$ & $79(60-98)$ \\
\hline \multicolumn{4}{|c|}{$\begin{array}{l}\text { Values are mean (SEM) or mean }(95 \% \mathrm{Cl}) \text {. } \\
\text { *Dilution space ratio: } 1.03(0.00) \text {; rate constant ratio: } 0.84(0.01) \text {. } \\
\quad 114 \text { measurements }(62 \text { ventilation mode); intra-measurement gas exchange variability }(95 \% \mathrm{Cl} \text { : } 7-9 \mathrm{CV} \%) \text {; day-to-day variability of } \\
\text { resting EE (95\% Cl: } 6-10 \mathrm{CV} \%) \text {; sampling time ventilation mode (mean: } 191 \text { min, range: } 30-710) \text {; sampling time canopy mode (mean: } \\
24 \text { min, range: } 15-40) \text {. }\end{array}$} \\
\hline
\end{tabular}

patients were slightly overfed (on average 13\% above total $\mathrm{EE}$ ) but the surgery patients were underfed (on average $40 \%$ below total EE). Mean respiratory quotient was 0.88 (range: $0.71-1.10)$ and significantly higher in the sepsis group $(0.91$; [95\% Cl: $0.87-0.94])$ compared to the surgery group $(0.86$; [95\% Cl: $0.85-0.88$ ], $P=0.005)$. The patients' mean daily body temperature did not change significantly over days during the study period. Resting EE was not different before and after weaning from mechanical ventilation (10 patients, $P=0.15)$.

\section{Physical activity}

Nine patients were included for this part of the study, but data of only seven patients were suitable for analysis (due to incomplete data acquisition in one patient and technical failure in reading out data in another). Six of the seven eligible patients had undergone surgery, and four of them were ventilated and sedated, but none of them underwent pharmacological muscle paralysis. Total and resting EE of these seven patients were not significantly different from the other 13 patients. Physical activity was present in each patient and mean accelerometry output over 6 days was 28 kcounts d $^{-1}$ (range: $12-49$ ). Activity related EE was strongly associated with the accelerometry data $\left(R^{2}=0.72\right.$, $P=0.02$ ) as shown in Figure 2. Mean PAL was 1.15 $(1.02-1.30)$ in these patients and showed a similar relation with the accelerometry results (data not shown). Mean dayto-day variation in activity is shown in Figure 3 , and shows no significant increase in activity from day 1 to 6 .

\section{Discussion}

The major finding of our study was that in critically ill children with sepsis, septic shock or following major abdominal or thoracic surgery, total EE was on average $22 \%$ higher than resting EE. We found large inter-individual variation in activity related EE and this was closely

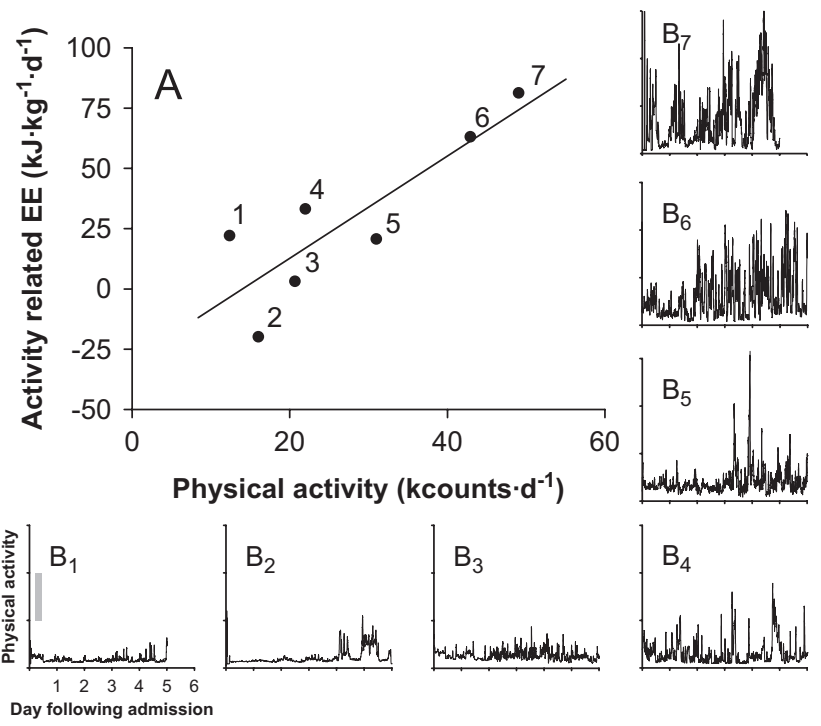

Figure 2 Relation between activity related EE and physical activity measurements of seven patients $(A)$, and the individual accelerometry recordings over time ( $B_{1-7}$, inset figures). $y$-Axis of inset figures indicates accelerometry counts; the unit is depicted in $B_{1}$ and equals 150 counts min $^{-1}$. Clinical characteristics (gender, age, body weight); all from surgery group except $B_{3}$ (sepsis): $B_{1}: M, 14 \mathrm{yr}, 41 \mathrm{~kg} ; B_{2}: M, 15 \mathrm{yr}, 52 \mathrm{~kg} ; B_{3}: F, 14 \mathrm{yr}$, $47 \mathrm{~kg} ; B_{4}: M, 5$ months, $6 \mathrm{~kg} ; B_{5}: M, 7 \mathrm{yr}, 21 \mathrm{~kg} ; B_{6}: F, 4$ months, $6 \mathrm{~kg} ; \mathrm{B}_{7}: \mathrm{F}, 2 \mathrm{yr}, 12 \mathrm{~kg}$.

correlated with body movement as measured independently by accelerometry.

Our finding that resting EE in patients was not elevated compared to healthy children of similar age and body weight, as predicted by Schofield's equations, is in agreement with findings using metabolic monitor measurements in children with sepsis treated with intensive care. ${ }^{22,23}$ This indicates that the patient's illness and treatment as such do not result in a hyper-metabolic state. Also, there was no 


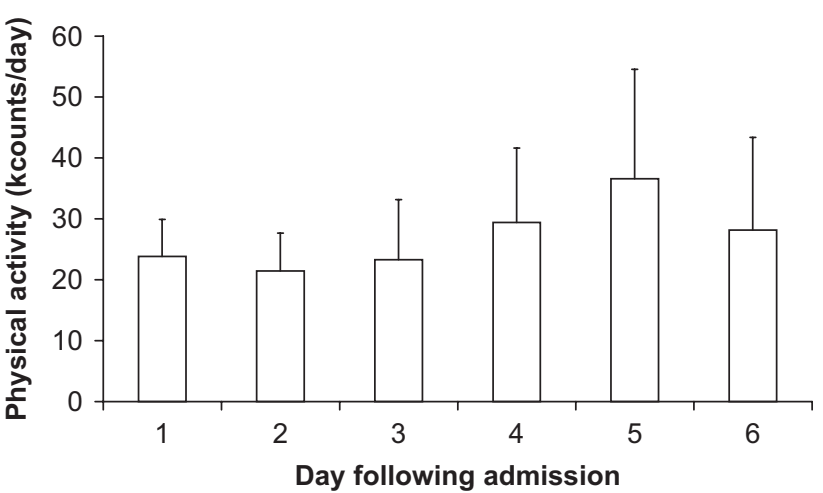

Figure 3 Day-to-day physical activity of seven critically ill children. Bars are daily means with $95 \%$ Cls. See footnote Fig. 2 for the patients' clinical characteristics.

significant development of measured resting EE over time, neither overall nor in the subgroups. Previous studies have assessed the course of EE over several days following PICU admission and did not report significant change over time either. ${ }^{24-27}$ This indicates the absence of a ebb (the period of severe shock characterised by depression of enzymatic activity and oxygen consumption) and flow phase (the subsequent hypermetabolic phase in which cardiac output and oxygen consumption are increased) in critically ill children. The contribution of dietary induced thermogenesis to resting $\mathrm{EE}$ and total $\mathrm{EE}$ in our study is assumed to be relatively small, as patients received mostly continuous tube feeding or parenteral nutrition.

The present study is the first to show that in two major categories of critically ill children, total EE is substantially higher than measured resting $\mathrm{EE}$, while the latter is regarded as a reliable guideline for nutritional support in these patients. Severity of illness did not appear to affect the PAL, as higher PRISM scores in the sepsis group did not translate into significantly lower activity related $\mathrm{EE}$. These results suggest that in children with sepsis or following recent surgery, energy intake should be higher than EE measured with a metabolic monitor during quiescence.

EE measurements in critically ill adults have indicated that total EE is approximately $10 \%$ higher than resting EE. This suggests that in critically ill adults a relatively small part of total EE may be attributed to activity related EE. ${ }^{14,15,28}$ Currently, predicted or resting EE are applied for approximation of total EE in critically ill infants and children. The underlying assumption that physical activity is either of low intensity or occurs infrequently, or both, should be assessed. Reduced skeletal muscle activity is plausible in healthy young infants confined to bed and healthy children during sleep. Less is known about PAL in critically ill children where $(A)$ frequent medical and nursing interventions interfere with bed-rest and (B) voluntary muscle activity is often limited by ubiquitous use of sedatives and/or muscle paralysis. Previous studies have indeed shown that these drugs reduce resting $\mathrm{EE}$ under certain conditions. ${ }^{7-9}$ In this study the origins of activity related $\mathrm{EE}$ were not addressed, since the accelerometry readings do not discriminate between active patient movements (skeletal muscle) and passive handling by caretakers (which will increase respiratory and cardiovascular work). In our observational study, the attending personnel may have been aware of the patient's resting $E E$, but total $E E$ and accelerometry recording were unknown to the researchers and caring personnel. It is thus unlikely that awareness or anticipation affected the findings with respect to elevated activity related $\mathrm{EE}$. In the patient group that underwent surgery, energy intake was significantly reduced and did not cover activity related or even resting EE. Underfeeding and malnutrition seems a general problem of hospitalised patients and especially intensive care patients. This is not due to lack of interest but mostly caused by the absence of robust and generally accepted guidelines for nutritional support in the paediatric intensive care setting, as we demonstrated in a European survey of 111 paediatric intensive care units. $^{29}$ In our study, some of the surgical patients had a low body mass index compared to healthy peers (mean: -0.4 , SDS: $1.9 \mathrm{~kg} / \mathrm{m}^{2}$ ). This was probably due to co morbidity and/or prior surgery and hospitalisation of this patient group. Extra attention should be paid to these patient while planning nutritional support. A good prognosis is most likely associated with nutritional status as shown in children with cystic fibrosis. ${ }^{30}$

We found a large inter-individual variation between resting $\mathrm{EE}$ and total EE. To explain these differences and to possibly tailor nutritional support of individual patients, it is of paramount importance to know whether this difference can be attributed to the energy cost of physical activity over time. In seven patients, the accelerometry recordings did explain the variance in physical activity related EE. These findings support the relevance of physical activity caused by major trunk muscle contractions and possibly rotation forces from moving extremities (and cost of increased cardiac output) as a determinant of total EE in critically ill infants and children. Moreover, accelerometry recordings showed high amplitude undulations over the day in some patients. This observation allows for explanation of the apparently discrepant results between total and resting $E E$. The association of activity related EE with accelerometry counts strongly indicated substrate utilisation due to energy expended in physical activity in critically ill children. However, some restraint is appropriate due to the limited number of subjects in our study (seven patients, six of whom underwent major surgery). Our results that physical activity is a strong determinant of total EE need to be further established in larger numbers of patients and different types of disease (e.g. sepsis and trauma). Some caution is also warranted, as activity related EE might be overestimated when underestimation of resting $E E$ occurs in the case of incomplete collection of exhaled air. ${ }^{31}$ Air leakage from the ventilator tube may occur because uncuffed tubes are preferably used in children (to prevent potential damage to the upper airway). Mean air leakage was assessed meticulously and did not exceed $5 \%$. Also, in half of the spontaneously breathing children we were confined to measure resting EE during sleep, which lowers EE with $5-10 \% .^{32}$ The combined effect could have resulted in the underestimation of resting $\mathrm{EE}$, but not higher than $\sim 5 \%$.

In our study, age and body weight were major determinants of resting EE but not of activity related EE. Trunk acceleration and deceleration (or rotation) multiplies with mass (or arm) to convert to aerobic energy and thus substrates used and carbon dioxide produced. It is thus 
expected that studies in larger numbers of patients over the complete age span of childhood will result in a relationship between tri-axial accelerometry recordings times body weight (or length) and activity related EE; this relationship has indeed been demonstrated in healthy free-living children. $^{33}$

In conclusion, we demonstrated a substantial difference between total daily EE and resting EE in acute critically ill children, while in clinical practice the latter is regarded as a reliable indicator for nutritional support. Independent measurement of physical activity with tri-axial accelerometry indicated that physical activity largely explained this difference. Hence, physical activity levels should be accounted for to avoid a negative energy balance and catabolism in critically ill children.

\section{Funding source}

The study was funded by the paediatric research foundation 'Stichting vrienden kinderkliniek'. Members of the foundation had no role in study design, collection, analysis and interpretation of the data, writing of the manuscript, and the decision to submit the manuscript for publication.

\section{Acknowledgements}

We thank Loek Wouters and Guy Plasqui (Human Biology, Maastricht University) for technical assistance and the nursing staff (VU University Medical Center) for assistance when performing measurements. We thank Jos Twisk (Institute of Research in Extramural Medicine, VU University Medical Center) for his statistical assistance and Michiel Oosterveld (Department of Pediatrics, VU University Medical Center) for text editing.

\section{Statement of authorship:}

MvdK designed the study protocol, included patients, executed the protocol, analysed the data and drafted the article. KdM contributed to study design, data analysis and drafting the article. KRW supervised the isotope and accelerometry study and contributed to data analysis and revision of the article. RJG designed and supervised the study and contributed to revision of the article.

Conflict of interest statement:

None declared.

\section{References}

1. Briassoulis G, Zavras N, Hatzis T. Malnutrition, nutritional indices, and early enteral feeding in critically ill children. Nutrition 2001;17:548-57.

2. Pollack MM, Ruttimann UE, Wiley JS. Nutritional depletions in critically ill children: associations with physiologic instability and increased quantity of care. J Parenter Enteral Nutr 1985; 9:309-13.

3. Mayes T, Gottschlich MM, Khoury J, Warden GD. Evaluation of predicted and measured energy requirements in burned children. J Am Diet Assoc 1996;96:24-9.

4. Bauer J, Hentschel R, Linderkamp O. Effect of sepsis syndrome on neonatal oxygen consumption and energy expenditure. Pediatrics 2002;110:e69.

5. van der Kuip M, Hoos MB, Forget PP, Westerterp KR, Gemke RJ, de Meer K. Energy expenditure in infants with congenital heart disease, including a meta-analysis. Acta Paediatr 2003;92: 921-7.

6. Phillips R, Ott L, Young B, Walsh J. Nutritional support and measured energy expenditure of the child and adolescent with head injury. J Neurosurg 1987;67:846-51.

7. Vernon DD, Witte MK. Effect of neuromuscular blockade on oxygen consumption and energy expenditure in sedated, mechanically ventilated children. Crit Care Med 2000;28: 1569-71.

8. Coss-Bu JA, Jefferson LS, Walding D, David Y, Smith EO, Klish WJ. Resting energy expenditure in children in a pediatric intensive care unit: comparison of Harris-Benedict and Talbot predictions with indirect calorimetry values. Am J Clin Nutr 1998;67:74-80.

9. Chwals WJ, Lally KP, Woolley MM, Mahour GH. Measured energy expenditure in critically ill infants and young children. J Surg Res 1988;44:467-72.

10. Schofield WN. Predicting basal metabolic rate, new standards and review of previous work. Hum Nutr Clin Nutr 1985;39S1: $5-41$.

11. Verhoeven JJ, Hazelzet JA, van der Voort E, Joosten KF. Comparison of measured and predicted energy expenditure in mechanically ventilated children. Intensive Care Med 1998;24: 464-8.

12. Taylor RM, Cheeseman P, Preedy V, Baker AJ, Grimble G. Can energy expenditure be predicted in critically ill children? Pediatr Crit Care Med 2003;4:176-80.

13. Vazquez Martinez JL, Martinez-Romillo PD, Diez SJ, Ruza TF. Predicted versus measured energy expenditure by continuous, online indirect calorimetry in ventilated, critically ill children during the early post injury period. Pediatr Crit Care Med 2004;5:19-27.

14. Weissman C, Kemper M, Elwyn DH, Askanazi J, Hyman Al, Kinney JM. The energy expenditure of the mechanically ventilated critically ill patient. An analysis. Chest 1986;89: 254-9.

15. Swinamer DL, Phang PT, Jones RL, Grace M, King EG. Twentyfour hour energy expenditure in critically ill patients. Crit Care Med 1987;15:637-43.

16. American College of Chest Physicians/Society of Critical Care Medicine Consensus Conference. Definitions for sepsis and organ failure and guidelines for the use of innovative therapies in sepsis. Crit Care Med 1992;20:864-74.

17. Pollack MM, Ruttimann UE, Getson PR. Pediatric risk of mortality (PRISM) score. Crit Care Med 1988;16:1110-6.

18. Gerver WJ, de Bruin R. Paediatric morphometrics, a reference manual, 2nd ed. Maastricht: University Press Maastricht; 2001.

19. Westerterp KR, Wouters L, van Marken Lichtenbelt WD. The Maastricht protocol for the measurement of body composition and energy expenditure with labeled water. Obes Res 1995; 3S1:49-57.

20. Hoos MB, Plasqui G, Gerver WJ, Westerterp KR. Physical activity level measured by doubly labeled water and accelerometry in children. Eur J Appl Physiol 2003;89:624-6.

21. Weir JBdeV. New methods for calculating metabolic rate with special reference to protein metabolism. Journal of Physiology 1946;109:1-9.

22. Turi RA, Petros AJ, Eaton S, et al. Energy metabolism of infants and children with systemic inflammatory response syndrome and sepsis. Ann Surg 2001;233:581-7.

23. Briassoulis G, Venkataraman S, Thompson AE. Energy expenditure in critically ill children. Crit Care Med 2000;28: 1166-72.

24. Oosterveld MJ, van der Kuip M, de Meer K, de Greef HJ, Gemke RJ. Energy expenditure and balance following pediatric intensive care unit admission: a longitudinal study of critically ill children. Pediatr Crit Care Med 2006;7:147-53. 
25. Turi RA, Petros AJ, Eaton S, Fasoli L, Powis M, Basu R, et al. Energy metabolism of infants and children with systemic inflammatory response syndrome and sepsis. Ann Surg 2001; 233:581-7.

26. Vazquez Martinez JL, Martinez-Romillo PD, Diez Sebastian J, Ruza Tarrio F. Predicted versus measured energy expenditure by continuous, online indirect calorimetry in ventilated, critically ill children during the early postinjury period. Pediatr Crit Care Med 2004;5:19-27.

27. De Klerk G, Hop WC, De Hoog M, et al. Serial measurements of energy expenditure in critically ill children: useful in optimizing nutritional therapy? Intensive Care Med 2002;28:1781-5.

28. Weissman C, Kemper M, Damask MC, Askanazi J, Hyman Al, Kinney JM. Effect of routine intensive care interactions on metabolic rate. Chest 1984;86:815-8.

29. van der Kuip $M$, van Bokhorst-de van der Schueren MA, de Meer K, Lafeber HN, Gemke RJ. Nutritional support in 111 pediatric intensive care units: a European survey. Intensive Care Med 2004;30:1807-30.

30. Beghin L, Gottrand F, Michaud L, et al. Impact of intravenous antibiotic therapy on total daily energy expenditure and physical activity in cystic fibrosis children with Pseudomonas aeruginosa pulmonary exacerbation. Pediatr Res 2003;5:756-61.

31. Joosten KF, Verhoeven JJ, Hop WC, Hazelzet JA. Indirect calorimetry in mechanically ventilated infants and children: accuracy of total daily energy expenditure with $2 \mathrm{~h}$ measurements. Clin Nutr 1999;18:149-52.

32. Fraser G, Trinder J, Colrain I M, Montgomery I. Effect of sleep and circadian cycle on sleep period energy expenditure. $J$ Appl Physiol 1989;66:830-6.

33. Ekelund U, Yngve A, Brage S, Westerterp K, Sjöström M. Body movement and physical activity energy expenditure in children and adolescents: how to adjust for differences in body size and age. Am J Clin Nutr 2004;79:851-6. 